\title{
Correlation between ultrasound and Magnetic Resonance Imaging in diagnosis of Ovarian Tumors
}

Tarek Mohamed M. Mansour ${ }^{1}$ MD; Mohamad Hasan Tawfik ${ }^{2}$ MD; Mohamed M. El-Barody ${ }^{3}$ MD; Sileem Ahmed Sileem ${ }^{4}$ MD ; Ahmed Okasha ${ }^{5} \mathrm{MD}$

* Corresponding Author:

Tarek Mohamed M. Mansour drtarekrad@gmail.com

Received for publication November 1, 2020; Accepted January 17, 2021; Published online January 17, 2021.

Copyright 2020 The Authors published by Al-Azhar University, Faculty of Medicine, Cairo, Egypt. All rights reserved. This an openaccess article distributed under the legal terms, where it is permissible to download and share the work provided it is properly cited. The work cannot be changed in any way or used commercially.

doi:10.21608/aimj.2021.47578.1343

${ }^{1}$ Radio-diagnosis department, Faculty of Medicine, Al-Azhar University, Assuit, Egypt

2 Radio-diagnosis department, Faculty of Medicine, Al-Azhar University, Cairo, Egypt

${ }^{3}$ Radio-diagnosis department , South Egypt cancer institute, Assuit University, Assuit, Egypt.

${ }^{4}$ Department of obstetrics and gynecology, Faculty of Medicine, AlAzhar University, Assuit, Egypt

${ }^{5}$ Radio-diagnosis department, Faculty of Medicine, south valley University, Qena, Egypt.

\begin{abstract}
ABSTRAC.
Background and objective: To discuss the value of ultrasound (US) and magnetic resonance imaging (MRI) in the evaluation of female patients with ovarian tumors.

Methods: This study was performed on 250 patients at University hospital and the National Cancer Institute who were referred to radiodiagnosis department from the Obstetric and Gynecology department during the period from March 2017 to March 2018. All patients were subjected to pathology assessment, transvaginal ultrasonography (TVUS) and MRI with diffusion-weighted imaging (MRI-DWI).

Results: The study group of 250 patients had a mean age of $38.85 \pm 17.1$ years. Lesions were classified according to histo-pathological analysis into benign (120 lesions, 48\%) and malignant (130 lesions, 52\%). Using US with Doppler, 105 cases were judged benign, and 145 cases were judged malignant. The sensitivity of the US with doppler examination the sensitivity was $81.51 \%$, with $93.9 \%$ specificity, The positive predictive value (PPV) was $91 \%$, and the NPV was $86 \%$. MRI analysis indicated that the mean dimension of benign tumors was $7.6 \pm 1.3 \mathrm{~cm}$, while the mean dimension of malignant tumors was $12.3 \pm 2.4 \mathrm{~cm}$ $(\mathrm{p}<0.001)$. The sensitivity of MRI was $96.43 \%$, specificity was $95.83 \%$, $\mathrm{PPV}$. The apparent diffusion coefficient (ADC) values were $1.85 \pm 0.58$ for benign tumors and $0.84 \pm 0.16$ for malignant tumors. MRI-DWI showed 100\% sensitivity, 93\% specificity, 95.5\% PPV, and 98\% NPV. Conclusion: MRI-DWI are promising techniques for the evaluation and characterization of ovarian cancer.
\end{abstract}

Key Words: Magnetic Resonance Imaging; ovarian neoplasms; ultrasonography; Diffusion.

Disclosure: The authors have no financial interest to declare in relation to the content of this article. The Article Processing Charge was paid for by the authors.

Authorship: All authors have a substantial contribution to the article.

\section{INTRODUCTION}

Ovarian cancer (OC) is an insidious disease that affects one out of every 74 women worldwide. ${ }^{1}$ The mortality rate of OC is higher than any other female reproductive cancer and, accordingly, OC is the 5th leading cause of cancer deaths among women worldwide. $^{2}$

In routine clinical practice, OC may be observed or identified indirectly in patients with asymptomatic disease. Characterization of OC provides a diagnostic challenge as it is essential to schedule effective therapeutic interventions in the preoperative setting, as well as to influence patient management. ${ }^{3,4}$

OC patients usually present with an advanced extrapelvic mass and this commonly results in a poor prognosis despite clinical progress and improved surgical techniques. ${ }^{5,6}$

During the assessment of an adnexal mass, the primary purpose of imaging is to differentiate benign from malignant masses. Management strategies may include extreme staging operations for suspected ovarian malignancies, less intrusive operations, potentially benign neoplasms (i.e., laparoscopy), avoiding procedures, and following benign injuries.

OC are classified based on tumor origin as metastatic, epithelial, germ cell, and sex cord-stromal cell tumors.

Sonography is the first imaging test to examine women with suspected adnexal masses due to its widespread availability, relatively low cost, and high sensitivity in mass detection. ${ }^{9}$ 
Nevertheless, it is restricted by its reduced specificity for benign tumors which can vary from 60 to $95 \% .{ }^{10}$

The transvaginal ultrasound (TVUS) is considered a better instrument to detect normal ovaries and ovarian lesions than transabdominal US, as transabdominal US may not image close enough to the pelvis and bowel loops which may affect resolution, whereas TVUS directly contacts the ovaries and uterus. ${ }^{11}$ The role of Doppler examination is to evaluate the presence of new vascularity inside the mass (central or peripheral).

Magnetic resonance imaging (MRI) offers valuable information for the classification of numerous ovarian masses as neoplastic or non-neoplastic, and benign or malignant. ${ }^{12}$

The use of MRI to diagnose ovarian masses involves a morphological consideration and signal intensity features on T1-weighted and T2-weighted images. ${ }^{13}$

In particular, improved MRI can help differentiate between benign and malignant tumors and may be useful to identify an adnexal mass. ${ }^{14}$

We focused this study on a discussion of the relative values of US/doppler and MRI in the evaluation of female patients with ovarian tumors.

\section{PATIENT AND MATERIALS}

\section{Study Design}

This retrospective study was performed on 250 patients who ranged from 13 to 70 years seen at the university hospital and the National Cancer Institute who were referred from the Obstetric and Gynecology department to the Radiodiagnosis department during the period from March 2017 to March 2018. All patients were subjected to detailed history with a particular focus on age, parity, menstrual history, previous history of gynecological disorders or operations, abdominal pelvic US, TVUS, color flow doppler, MRI, and histopathological review. No exclusion criteria except the claustrophobic patients.

\section{US Imaging}

US imaging was performed using a General Electric medical system logic P5, Siemens acuson X300, and Mindray DC3. All patients were examined in the supine position and, where possible, patients were asked to fast for at least eight hours before the study. The ultrasound scans, were reviewed by two experienced radiologists ( $\mathrm{MH}, \mathrm{AO})$ and gynecological (SA) consultants based on the International Ovarian Tumor Analysis (IOTA) simple-rules. We examined the site of the tumors (right, left, or both), tumor size, tumor shape (rounded or oval), tumor echogenicity (hypo, iso, or hyperechoic), presence of vegetation or septation (if cystic), wall of the tumor (regular or not), Doppler vascularity of the content, containing cystic degeneration, soft tissue nodules, fat content (or not), compression of other organs (or not), suggestive benign or malignant staging of the tumor, presence of pelvic para iliac lymph node invasion (or not), and the presence of ascites or peritoneal nodules.

MRI was performed by a Phillips Achieva 1.5T system. Using a pelvic phased-array Torso coil, the all patients were imaged in the supine position. To minimize bowel peristalsis, intravenous administration of an antispasmodic drug (10 mg of visceralgine) was administered immediately prior to MRI. As feasible, patients were instructed to fast eight hours before the test. Non-contrast MRI protocol was applied T1-weighted axial (TR / TE, 500/10 ms), T2-weighted axial (TR / TE, 3300/100 $\mathrm{ms})$, T2-weighted sagittal, and T2-weighted coronal. Before the administration of the contrast medium, MRI-DWI was acquired in the axial plane using a single-shot echo-planar imagery sequence. The MRI exam. were reviewed by three experienced radiolodists (TM, AO and MB) consultants.

\section{Histopathological correlation}

The histo-pathological evaluation is the gold standard for ovarian cancer diagnosis regardless of the findings on US or MRI. According to the post surgical histo-pathological results (180), lesions were divided into benign and malignant groups.

Image analysis for US, Doppler study and MRI-DWI The ultrasound grey scale confirms the presence of cystic or solid ovarian mass and was analyzed for size, site, inner wall surface (smooth, irregular, papillae or solid projections), wall thickness (thin, thick or mostly solid), septae (presence, thin or thick) and echogenicity of tumor sonolucent, low echogenicity, low echogenicity with echogenic core, mixed echogenicity, high echogenicity).

Following gray scale scanning, color flow signals were superimposed in real time and the regions of intratumoral neovascularisation were identified as location of vessels was central (solid areas, septa and papillae) or peripheral (around a cyst or a liquid area). The spectral wave forms were obtained from which the pulsatility and resistive indices were noted (PI and RI). The range of values of PI for malignant masses was 0.48 to 1.33 with a mean of 0.85 . PI of benign masses ranged from 1.3 to 7.4 with mean standing at 3.15, by using a PI value of 1.1 as the cutoff point, for differentiating benign and malignant lesions.

The range of values of RI for malignant masses was 0.4 to 0.98 with a mean of 0.5 . RI of benign masses ranged from 0.4 to 0.9 with mean standing at 1.05 , using an RI value of 0.6 as the cut-off point.

In MRI and diffusion three experienced radiologists observed the images (TM, AO and MB), The conventional $\mathrm{MR}$ images were analyzed and evaluated for the site (RT/LT), size, shape, and complexity of the tumor, T2 signal intensity of the solid part inside the mass and the presence of ascites and peritoneal deposits as well as lymph nodes. In MR-diffusion the lesions with low signal on diffusion images and high signal in the ADC maps assigned for free diffusion and diagnosed as benign masses, while Lesions with high signal on diffusion 
images with low signal in the corresponding ADC maps assigned for restricted diffusion and diagnosed as malignant masses, In ADC map we selected the region of interest (ROI) manually on the solid and the cystic component of the tumors, which was then automatically calculated on the work station to get the ADC values.

Statistical Analysis

All continuous data are presented as mean $\pm \mathrm{SD}$, median, and range while qualitative data are described in frequencies (number of cases) and percentages. Accuracy was demonstrated by the following terms: sensitivity, specificity, positive predictive value (PPV), negative predictive value (NPV), and overall accuracy. To define the optimum cut-off for the diagnostic markers studied, receiver operator characteristic (ROC) analysis was used. The student t-test for independent samples was used to compare numerical variables between study groups. Chi-square $(\chi 2)$ test was performed to compare categorical results. Alternatively, exact tests were used when the predicted frequency was below 5 . A pvalue of less than 0.05 was considered statistically significant. All statistical analyses have been conducted using Microsoft Windows version 22 of SPSS (Chicago, IL, USA).

\section{RESULTS}

This study enrolled 250 patients (98 patient post menopausal) with a mean age of $38.85 \pm 17.1$ years. Malignant tumors were more commonly found in older patients (38.85 years) compared to benign tumors (36 years). Neoplasms were classified according to histopathological examination into 120 benign and 130 malignant tumors.

Benign tumors included 15 serous cystadenomas, 15 mucinous cystadenomas, 25 dermoid cysts Figure (1), 15 benign dysgerminomas, 10 chocolate cyst, 5 granulosa cell tumor, 5 fibrothecoma Figure (2), 15 simple cysts, 5 tubo-ovarian abscess Figure (3), 5 spindle cell tumor (histo-pathological term of low grade sarcoma), and 5 hemorrhagic cyst.

Malignant tumors included 15 mucinous cystadenocarcinomas, 5 dysgerminoma, 15 serous cystadenocarcinomata, 5 metastatic tumor, 5 invasive high-grade mucinous carcinoma, 5 immature teratoma, 5 borderline tumors, 5 malignant hemorrhagic cyst, and 65 cases are classified pathologically as high grade ovarian carcinoma Table (1).

\section{Analysis of ovarian tumors by the US}

Lesions were classified pathologically by US into 105 benign cases, and 145 malignant cases Table (2). The sensitivity of the US was $43.75 \%$, with $26.9 \%$ specificity. The positive predictive value (PPV) was $31.34 \%$, and the negative predictive value was $38.64 \%$. (Figure 4) shows the ROC curve of the US data obtained (Table 3). Twenty-six (26) were classified as complex tumors (52\%), 17 (34\%) as cystic tumors, and $7(14 \%)$ as solid tumors. The majority (48) of tumors were unilateral (96\%), and only two tumors were bilateral. In terms of Solid vegetation, 29 (58\%) were equal or greater than one centimeter, and 21 (42\%) were less than one centimeter. After dopper examination the sensitivity was $81.51 \%$, with $93.9 \%$ specificity, The positive predictive value (PPV) was 91\%, and the negative predictive value was $86 \%$.

\section{Analysis of ovarian tumors by MRI}

The mean dimension of the benign neoplasms measured was $7.6 \pm 1.3 \mathrm{~cm}$, while the mean dimension of malignant tumors was $12.3 \pm 2.4 \mathrm{~cm}$, with a highly significant difference between both types $(p<0.001)$. Tumor composition, laterality of the lesions, and solid vegetation of the lesions were similar to those observed using US. However, the sensitivity of MRI was $96.43 \%$, specificity was 95.83\%, PPV was 96.43\%, and NPV 95.83\% Figure (5), Table (4).

MRI were found 22 cases with the criteria of malignant lesions (tumors larger than $6 \mathrm{~cm}$, septae more than $3 \mathrm{~mm}$, and solid vegetation more than 1 $\mathrm{cm}$ with thick wall). Three cases (two mature teratomas and one serous cystadenoma) identified as benign by pathology were presumed to be malignant by MRI Table (5). Analysis of one patient with mucinogenic cystadenocarcinoma assumed that the tumor was benign because by MRI analysis there were no septations or solid nodules, but pathology later proved this to be a malignant tumor.

\section{Analysis of ovarian tumors by DWI}

In terms of diffusion-weighted imaging (DWI), the apparent diffusion coefficient (ADC) values were $1.85 \pm 0.58$ for benign tumors, and $0.84 \pm 0.16$ for malignant tumors (Table 6). MRI-DWI showed 100\% sensitivity, 93\% specificity, 95.5\% PPV, and 98\% NPV Figure (6), Table (7).

Regarding the difference between MRI-DWI and pathology, restriction by MRI-DWI refers to low ADC values. Specifically, a low signal in a corresponding ADC map and high signal in diffusion images was observed in 130 patients but tumors were proven to be malignant by pathology. Alternatively, 120 patients showed facilitated diffusion (high ADC values, high signal on corresponding ADC map, and low signal in diffusion images). These tumors were later proven to be benign by pathological examination.

35 cases of the 130 initially characterized as malignant were later proven to be false positives as 5 were pathologically classified as mature teratomas, 5 fibrothecoma, 5 tubo-ovarian abscess, and 10 cases of chocolate cyst. Each proved to have a benign pathology with high signal on diffusion images (restriction) but the low signal on corresponding ADC map and ADC values 1.1 to $0.8 \times 10-3 \mathrm{~mm}$ Table (8).

The diagnosis of such lesions was depended on the combination of the other MRI sequences with the MRI-diffusion and the ADC map/ value. 


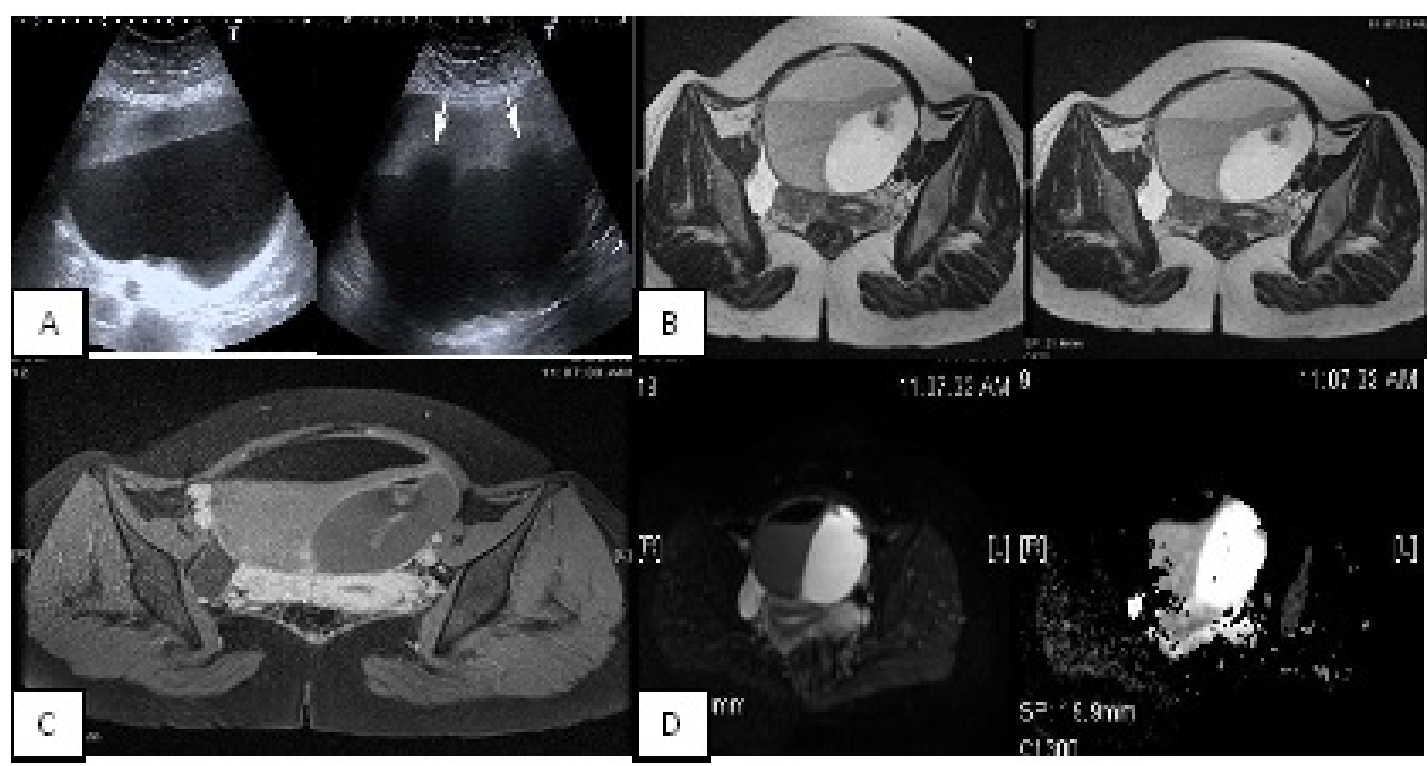

Figure 1: Analysis of a 32 year old female patient complaining of lower abdominal pain. (A) Axial trans abdominal US scan shows a well defined mass lesion at the right adnexal region with hyper and hypo echoic pattern. The mass has cystic components and fluid level. (B) Axial T2-wighted image, and (C) Axial T1 fat saturation images show high T1 and T2 weighted images with loss of signal in and out of phase and fat suppression images consistent with fat content. (D) MRI-DWI and ADC shows high signal on both MRI-DWI and ADC (T2 shine-through effect). The lesion was diagnosed by histopathology as a mature cystic teratoma.

Figure 2: Analysis of a 60 year old female patient complaining of abdominal pain. (A) US images shows a large

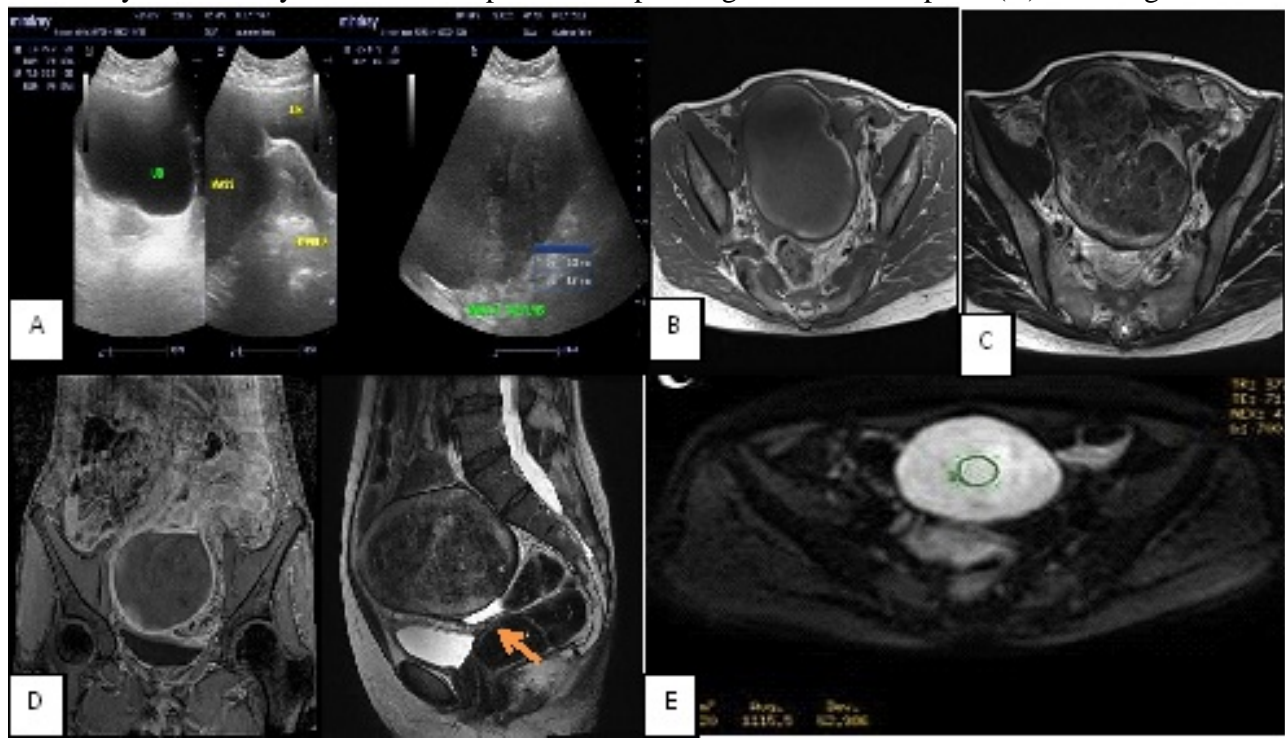

well-defined, encapsulated, isoechoic right adnexal soft tissue mass lesion with areas of small cystic degeneration with no invasion of the surrounding structure. MRI indicates a right adnexal mass, lobulated, well-defined and encapsulated with heterogeneous structure associated with signal intensities sugg. of internal fibrosis, small cystic changes, and peripheral hemorrhage. This mass was hypointense at T1 weighted image (B) and T2 weighted image (C) with peripheral enhancement on T1 fat saturation (D). The mass also shows no evidence of fat, minimal amount of free peritoneal fluid collection (arrow) on (D) sagittal T2. (E) The lesion appeared as a homogeneous hyperintense signal on the ADC map. The lesion was proved by histopathology to be a fibrothecoma of the right ovary with myxoid degeneration, intact capsule, and no malignancy. 


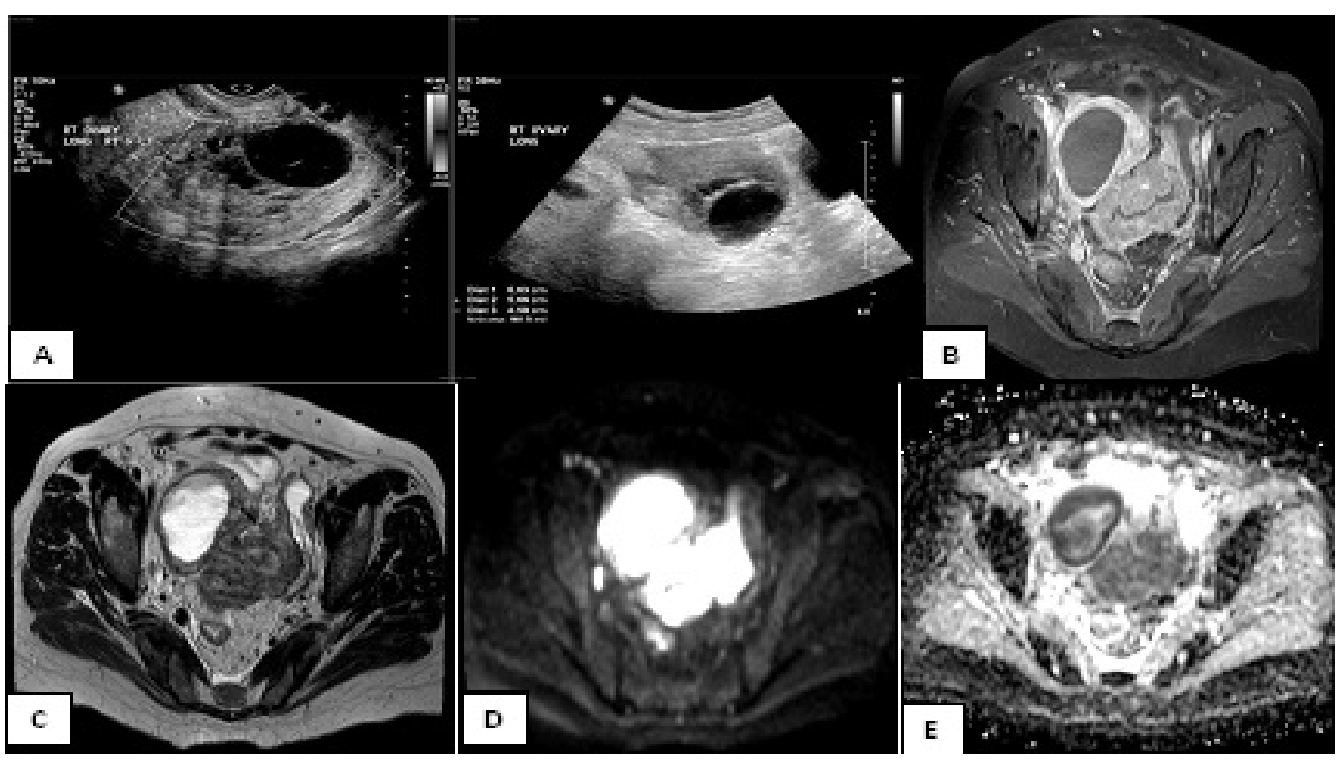

Figure 3: Analysis of a 46 year old female patient who presented with lower abdominal pain and fever. (A) Trans abdominal and TVUS, revealed the right adnexa contains a complex, predominantly cystic mass lesion of thick wall, turbid contents, and fine septation associated with a small amount of free pelvic fluid collection at the Douglas pouch. The lesion also shows peripheral vascularization on color Doppler study. The right adnexa shows a well defined cystic lesion measuring about $5.7 \times 6.7 \mathrm{~cm}$ in maximum dimensions. It displays hypointense signal with peripheral enhancement on post-contrast T1 weighted image (B), hyperintense signal on T2 weighted image (C). MRI-DWI (D) indicates the lesion shows high signal intensity with a low ADC map (E) (low ADC value indicates true diffusion restriction). The lesion was diagnosed by pathology as a right adnexal tubo-ovarian abscess with no malignant cells.

\section{US}

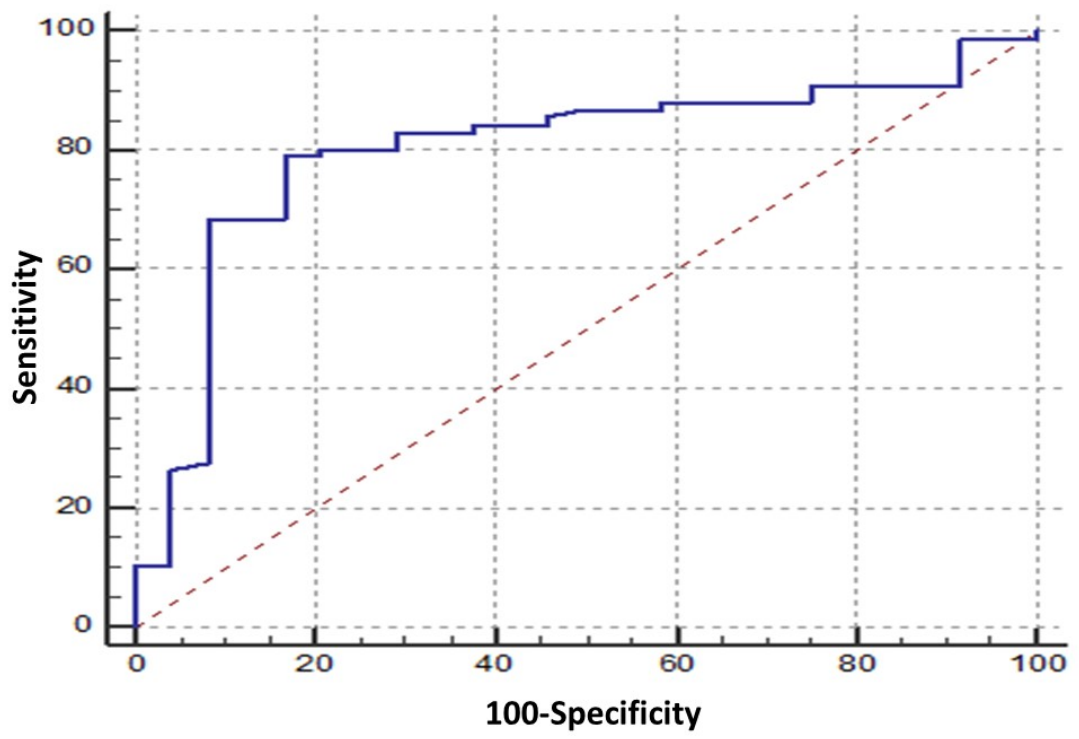

Figure 4: ROC curve indicating the diagnostic accuracy of US for detection of ovarian tumors. 


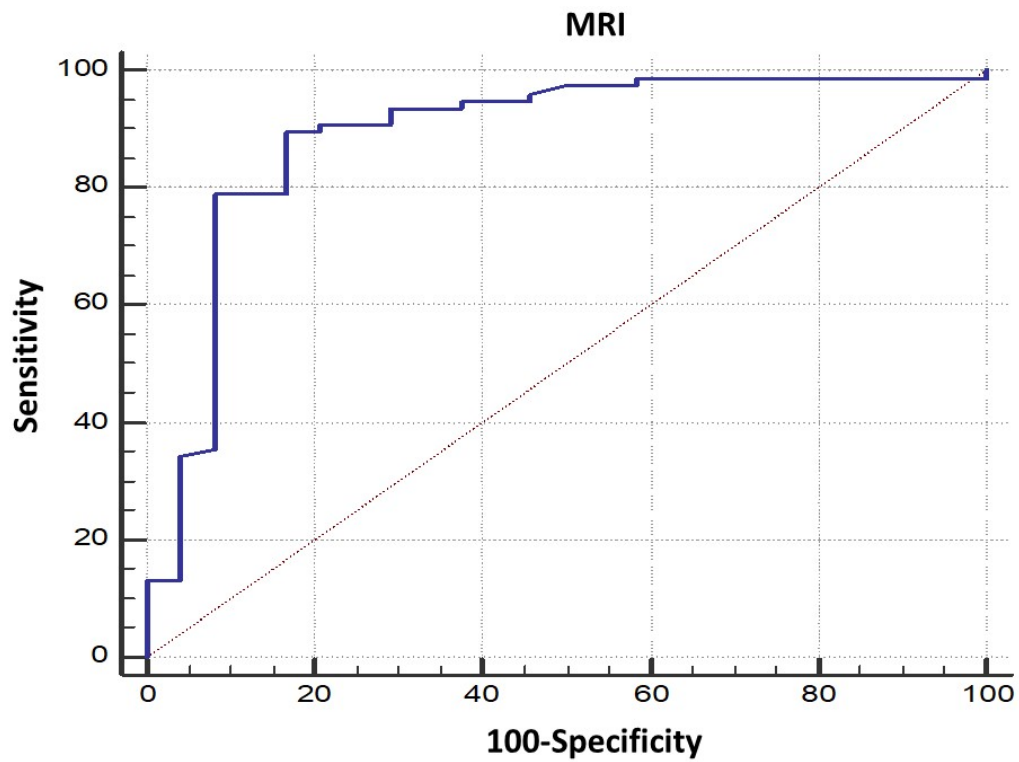

Figure 5: ROC curve indicating the diagnostic accuracy of MRI for detection of ovarian tumors.

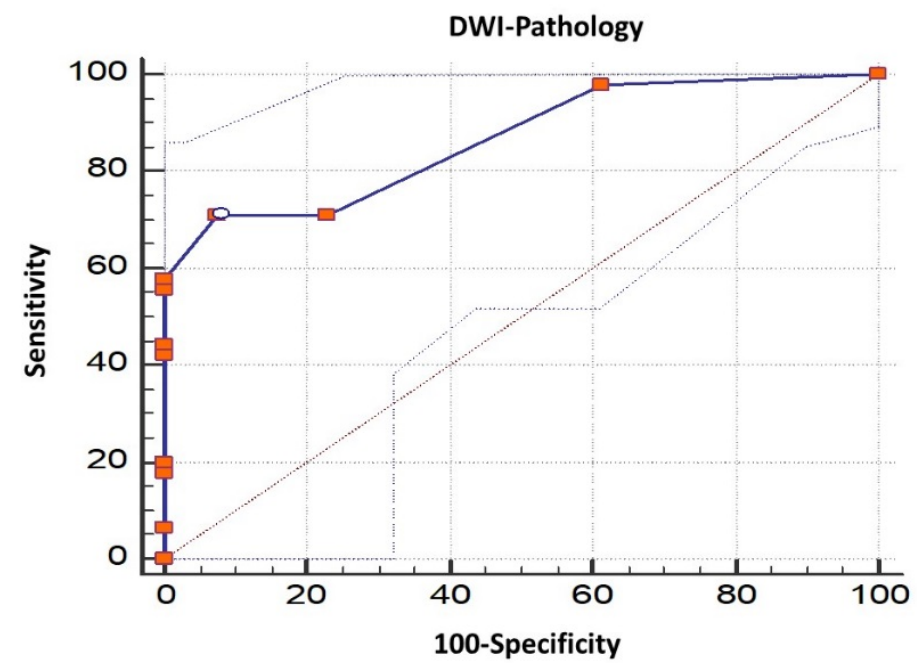

Figure 6: ROC curve indicating the diagnostic accuracy of MRI-DWI for detection of ovarian tumors.

\begin{tabular}{|c|c|c|c|}
\hline & Types & $\mathbf{N}$ & $\%$ \\
\hline \multirow{10}{*}{$\begin{array}{l}\text { Benign } \\
\mathrm{N}=120\end{array}$} & Simple cyst & 15 & 12.5 \\
\hline & Serous cyst adenoma & 15 & 12.5 \\
\hline & $\begin{array}{l}\text { Mucinous cyst } \\
\text { adenoma }\end{array}$ & 15 & 12.5 \\
\hline & Dermoid cyst & 25 & 20.8 \\
\hline & dysgerminoma & 15 & 12.5 \\
\hline & Chocolate cyst & 10 & 8.3 \\
\hline & Tubo-ovarian abscess & 5 & 4.2 \\
\hline & Spindle cell tumor & 5 & 4.2 \\
\hline & Hemorrhagic cyst & 5 & 4.2 \\
\hline & Granulosa cell tumor & 5 & 4.2 \\
\hline
\end{tabular}




\begin{tabular}{|c|c|c|c|}
\hline & Fibrothecoma & 5 & 4.2 \\
\hline \multirow[t]{10}{*}{$\begin{array}{c}\text { Malignat } \\
\mathrm{N}=\mathbf{1 3 0}\end{array}$} & $\begin{array}{l}\text { Advanced ovarian } \\
\text { cancer }\end{array}$ & 65 & 50.0 \\
\hline & $\begin{array}{c}\text { Serous } \\
\text { cystadenocarcinoma }\end{array}$ & 15 & 11.5 \\
\hline & $\begin{array}{c}\text { Mucinous } \\
\text { cystadenocarcinoma }\end{array}$ & 15 & 11.5 \\
\hline & METs metastasis & 5 & 3.8 \\
\hline & $\begin{array}{l}\text { Invasive high grade } \\
\text { mucinous carcinoma }\end{array}$ & 5 & 3.8 \\
\hline & $\begin{array}{c}\text { Minimal represented } \\
\text { carcinoma }\end{array}$ & 5 & 3.8 \\
\hline & $\begin{array}{l}\text { Malignant hemorrhagic } \\
\text { cyst }\end{array}$ & 5 & 3.8 \\
\hline & Immature teratoma & 5 & 3.8 \\
\hline & $\begin{array}{c}\text { Malignant } \\
\text { dysgerminoma }\end{array}$ & 5 & 3.8 \\
\hline & Borderline tumor & 5 & 3.8 \\
\hline
\end{tabular}

Table 1: The different pathological types.

\begin{tabular}{|c|c|c|}
\hline & & \\
\hline Types: & $\mathbf{N}=250$ & $\%$ \\
\hline Benign & 105 & 42.0 \\
\hline Malignant & 145 & 58.0 \\
\hline Total & 250 & 100 \\
\hline
\end{tabular}

Table 2: Represents the pathological types according to US.

\begin{tabular}{cccccc} 
Marker & Significance & Sensitivity & Specificity & PPV & NPV \\
\hline US & 0.52 NS & $43.75 \%$ & $26.9 \%$ & $31.34 \%$ & $38.64 \%$ \\
\hline
\end{tabular}

Table 3: ROC curve for Results of US compared to pathology.

\begin{tabular}{cccccc} 
Marker & Significance & Sensitivity & Specificity & PPV & NPV \\
\hline MRI & $<0.001$ HS & $96.43 \%$ & $95.83 \%$ & $96.43 \%$ & $\begin{array}{c}95.83 \\
\%\end{array}$
\end{tabular}

Table 4: ROC curve for results of MRI compared to pathology.

\begin{tabular}{|c|c|c|}
\hline Pathology: & N=250 & $\%$ \\
\hline Benign & 120 & 48.0 \\
\hline Malignant & 130 & 52.0 \\
\hline
\end{tabular}

Table 5: The pathological type according to MRI.

\begin{tabular}{|c|c|c|}
\hline \multicolumn{1}{|c|}{ Types: } & $\mathbf{N}=250$ & $\%$ \\
\hline Benign & 120 & $\mathbf{4 8 . 0}$ \\
\hline Malignant & 130 & 52.0 \\
\hline
\end{tabular}

Table 6: Represents the pathological types according to DWI. 


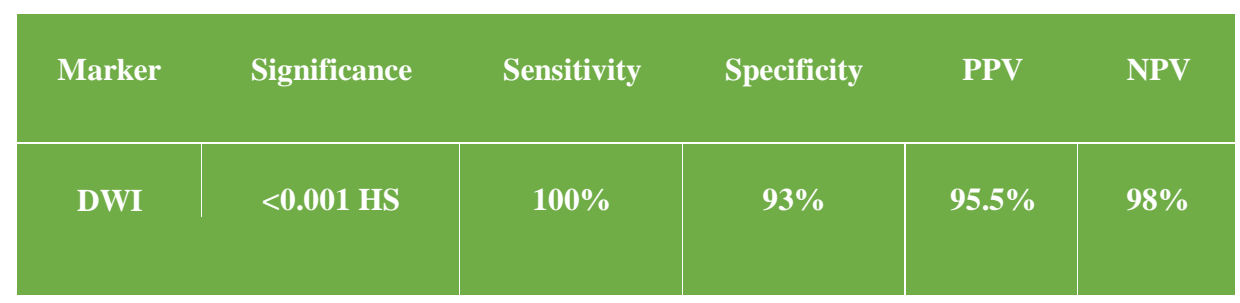

Table 7: ROC curve for results of DWI compared to pathology.

\begin{tabular}{|c|c|c|c|c|c|c|}
\hline ADC & $\mathbf{N}$ & Mean & SD & Minimum & Maximum & Median \\
\hline Benign & 120 & 1.85 & 0.5852 & 1.3 & 3 & 1.85 \\
\hline Malignant & 130 & 0.84 & 0.1651 & 0.6 & 1.1 & 0.85 \\
\hline Total & 250 & 1.354 & 0.6697 & 0.6 & 3 & 1.2 \\
\hline
\end{tabular}

Table 8: Shows the comparison between the ADC values between benign and malignant tumors

\section{DISCUSSION}

Based on the literature, timely management of OC relies on proper preoperative assessment using clinical examinations, laboratory tests, and different imaging methods. ${ }^{6,7}$ In post-menopausal women, unnecessary surgeries can be avoided by accurate adnexal mass classification. Alternately, in young women, limiting unnecessary surgeries can help to preserve childbearing capability. ${ }^{15}$ It was reported that MRI is more specific and accurate than Doppler and US assessment, especially in characterizing adnexal masses and that MRI is the best way to delineate local distribution to pelvic organs. ${ }^{16}$

Diffusion-weighted imaging (DWI) is a promising technique for practical and significant efficiency in the differentiation between benign and malignant adnexal masses. ${ }^{17,18}$ The concept of DWI is to introduce a gradient area on the basis of a conventional SE series, respectively, in front and at the back of a $180^{\circ}$ based radio frequency pulse, where the two gradient areas are symmetrical in location but have opposite polarization. ${ }^{19,20}$ As water molecules scatter under the gradient field action, the transverse magnetized protons are filtered out and cannot be completely aggregated. This contributes, in turn, to signal dilution and irregular signaling on the DWI. ${ }^{21,22}$ The ADC values may measure the size of the molecular expansion movement of water. Numerous tissues and pathophysiological processes have numerous ADC values ${ }^{23}$ and variance in the $\mathrm{ADC}$ value can represent changes in the disease's general and microscopic structures

In this study, our findings indicate that TVUS was not sufficiently accurate in differentiating between benign and malignant tumors. In contrast, MRI and MRI-DWI provided highly significant and accurate results. Michielsen et al. ${ }^{24}$ conducted a clinical feasibility study to compare whole body DWI-MRI and computerized tomography (CT) in patients with suspected ovarian cancer. They reported that DWIMRI showed high accuracy in primary tumors characterization (94\%) and peritoneal staging (91\%) compared to CT.

Our findings demonstrated that the ADC values were higher in benign tumors compared to malignant tumors. This finding is supported by the study of Zhuang and colleagues. ${ }^{25}$, who reported that the solid ADC in the benign group was significantly higher than the malignant group. The explanation for this may be that there was a higher rate of proliferation of malignant cells and a relatively small cell distance with a high molecular activity of water. This means that ADC rates measured in malignant tumors were slightly lower than normal rates. These findings suggest that DWI may be used as a differential diagnostic technique for the treatment of malignant solid and cystic ovarian tumors.

Sohaib et al. ${ }^{26}$ identified that malignant lesions showed more development than benign lesions in the early stage of improvement than in the late stage of improvement. Additionally, while benign ovarian tumors showed a gradual improvement without a well-defined peak, the borderline ovarian tumors showed a moderate initial increase and a plateau.

A recent study identified that the pattern of enhancement was overlapping with the use of all half-quantitative parameters (peak and MR enhancement) between benign and malignant classes, but most malignant showed peak times in 60 seconds or less and average MR enhancement of 80 or more. ${ }^{27}$

Pégah and colleagues performed another study on 65 pelvic mass patients ( 36 benign, 22 malignant, and 
seven boundary cases). These investigators observed an early, rapid, and steep development followed by the washout, and a plateau curve was seen mostly with borderline, benign tumors, and 11 malignant cases. ${ }^{28}$ For invasive lesions, the initial region under the curve was substantially greater in the first 60 seconds (IAUC-60) than for benign and borderline masses.

CA125 has the advantage of post-operative screening as it increases several months before the clinical recurrence of ovarian cancer however, it has low specificity as it increases in non-neoplastic diseases such as fibroids, PID, and endometriosis as well as in pregnancy.

Antila et al. reported no significant differences in preoperative CA125 values in primary ovarian tumour and ovarian metastasis. On the other hand, they also reported that CEA was significantly elevated in ovarian metastasis compared to POC. ${ }^{29}$

This study highlighted that simple cystic tumors have regular, well defined thin walls, clear contents, with no septation, calcification, nor solid component. Complex benign-looking masses possess hyperechoic contents considered either fat or blood. In terms of malignant tumors, malignant cystic masses show irregular outlines, ill-defined, thick wall, turbid contents with thick septation, calcification, and solid component. This study also has some limitations, such as insufficient data regarding the demographic and clinical characteristics of included patients which may contribute to risk factors. Another limitation is the lack of details regarding associated biomarkers. Further, DWI and dynamic study interpretation should be in conjunction with other morphological criteria in conventional MRI sequences.

\section{CONCLUSION}

In conclusion, MRI and MRI-DWI can differentiate between benign and malignant ovarian lesions and are promising techniques in the evaluation and characterization of OC. Patients with tuboovarian abscess are best to be avoided as, in these cases, DWI findings are misleading and can give false results. So, follow-up studies is recommended to add the value of contrast on MRI technique.

\section{REFERENCES}

1. Brett M. R, Jennifer B. P, Thomas A. S, Brett M. R, Jennifer B. P, Thomas A. S. Epidemiology of ovarian cancer: a review. Cancer Biol Med [Internet]. 2017;14(1):9-32. Available from: http://www.cancerbiomed.org/index.php/cocr/articl e/view/1004.

2. Momenimovahed Z, Tiznobaik A, Taheri S, Salehiniya H. Ovarian cancer in the world: epidemiology and risk factors. Int $J$ Womens Health [Internet]. 2019 Apr;Volume 11:287-99. Available from: https://www.dovepress.com/ovarian-cancer- in-the-world-epidemiology-and-risk-factors-peerreviewed-article-IJWH

3. Di Lorenzo G, Ricci G, Severini GM, Romano F, Biffi S. Imaging and therapy of ovarian cancer: clinical application of nanoparticles and future perspectives. Theranostics [Internet]. 2018;8(16):4279-94. Available from: http://www.thno.org/v08p4279.htm

4. Grayson K, Gregory E, Khan G, Guinn B-A. Urine Biomarkers for the Early Detection of Ovarian Cancer - Are We There Yet? Biomark Cancer [Internet]. 2019 Jan 26;11:1179299X1983097. Available from: http://journals.sagepub.com/doi/10.1177/1179299X 19830977

5. Lisio M-A, Fu L, Goyeneche A, Gao Z, Telleria C. High-Grade Serous Ovarian Cancer: Basic Sciences, Clinical and Therapeutic Standpoints. Int J Mol Sci [Internet]. 2019 Feb 22;20(4):952. Available from: http://www.mdpi.com/14220067/20/4/952

6. Chandra A, Pius C, Nabeel M, Nair M, Vishwanatha JK, Ahmad S, et al. Ovarian cancer: Current status and strategies for improving therapeutic outcomes. Cancer Med [Internet]. 2019 Nov 27;8(16):7018-31. Available from: https://onlinelibrary.wiley.com/doi/abs/10.1002/ca $\mathrm{m} 4.2560$

7. Forstner R, Thomassin-Naggara I, Cunha TM, Kinkel K, Masselli G, Kubik-Huch R, et al. ESUR recommendations for $\mathrm{MR}$ imaging of the sonographically indeterminate adnexal mass: an update. Eur Radiol [Internet]. 2017 Jun 21;27(6):2248-57. Available from: http://link.springer.com/10.1007/s00330-016-46003

8. Shim S-H, Kim D-Y, Lee S-W, Park J-Y, Kim J-H, Kim Y-M, et al. Laparoscopic Management of Early-Stage Malignant Nonepithelial Ovarian Tumors. Int J Gynecol Cancer [Internet]. 2013 Feb;23(2):249-55. Available from: https://ijgc.bmj.com/lookup/doi/10.1097/IGC.0b013 e318272e754

9. Smorgick N, Maymon R. Assessment of adnexal masses using ultrasound: a practical review. Int $J$ Womens Health [Internet]. 2014 Sep;857. Available from: http://www.dovepress.com/assessment-ofadnexal-masses-using-ultrasound-a-practicalreview-peer-reviewed-article-IJWH

10. Sehgal N. Efficacy of color doppler ultrasonography in differentiation of ovarian masses. $J$ Midlife Health [Internet]. 2019;10(1):22. Available from: http://www.jmidlifehealth.org/text.asp?2019/10/1/ 22/255277

11. Kurjak A, Shalan H, Kupesic S, Predanic M, Zalud I, Breyer B, et al. Transvaginal color Doppler sonography in the assessment of pelvic tumor vascularity. Ultrasound Obstet Gynecol [Internet]. 1993 Mar 1;3(2):137-54. Available from: http://doi.wiley.com/10.1046/j.14690705.1993.03020137.x

12. Foti PV, Attinà G, Spadola S, Caltabiano R, Farina $\mathrm{R}$, Palmucci $\mathrm{S}$, et al. MR imaging of ovarian masses: classification and differential diagnosis. Insights Imaging [Internet]. 2016 Feb 16;7(1):2141. Available from: 
http://link.springer.com/10.1007/s13244-0150455-4

13. Valentini AL, Gui B, Miccò M, Mingote MC, De Gaetano AM, Ninivaggi V, et al. Benign and Suspicious Ovarian Masses-MR Imaging Criteria for Characterization: Pictorial Review. J Oncol [Internet]. 2012;2012:1-9. Available from: http://www.hindawi.com/journals/jo/2012/481806

14. Thomassin-Naggara I, Balvay D, Rockall A, Carette MF, Ballester M, Darai E, et al. Added Value of Assessing Adnexal Masses with Advanced MRI Techniques. Biomed Res Int [Internet]. 2015;2015:1-10. Available from: http://www.hindawi.com/journals/bmri/2015/7852 06/

15. Kaijser J, Sayasneh A, Van Hoorde K, GhaemMaghami S, Bourne T, Timmerman D, et al. Presurgical diagnosis of adnexal tumours using mathematical models and scoring systems: a systematic review and meta-analysis. Hum Reprod Update [Internet]. 2014 May 1;20(3):449-62. Available from: https://academic.oup.com/humupd/articlelookup/doi/10.1093/humupd/dmt059

16. Mohaghegh P, Rockall AG. Imaging strategy for early ovarian cancer: Characterization of adnexal masses with conventional and advanced imaging techniques. Radiographics. 2012;32(6):1751-73 .

17. Taouli B, Beer AJ, Chenevert T, Collins D, Lehman C, Matos C, et al. Diffusion-weighted imaging outside the brain: Consensus statement from an ISMRM-sponsored workshop. J Magn Reson Imaging [Internet]. 2016 Sep;44(3):521-40. Available from: http://doi.wiley.com/10.1002/jmri.25196

18. Kim H-J, Lee S-Y, Shin YR, Park CS, Kim K. The Value of Diffusion-Weighted Imaging in the Differential Diagnosis of Ovarian Lesions: A Meta-Analysis. Cao C, editor. PLoS One [Internet]. 2016 Feb 23;11(2):e0149465. Available from:

http://dx.plos.org/10.1371/journal.pone.0149465

19. Elhelaly AE, AlBasher G, Alfarraj S, Almeer R, Bahbah EI, Fouda MMA, et al. Protective effects of hesperidin and diosmin against acrylamideinduced liver, kidney, and brain oxidative damage in rats. Environ Sci Pollut Res [Internet]. 2019 Nov 4; Available from: http://link.springer.com/10.1007/s11356-01906660-3

20. Chilla GS, Tan CH, Xu C, Poh CL. Diffusion weighted magnetic resonance imaging and its recent trend-a survey. Quant Imaging Med Surg [Internet]. 2015 Jun;5(3):407-22. Available from: http://www.ncbi.nlm.nih.gov/pubmed/26029644

21. Etheridge ML, Hurley KR, Zhang J, Jeon S, Ring HL, Hogan C, et al. Accounting for biological aggregation in heating and imaging of magnetic nanoparticles. TECHNOLOGY [Internet]. 2014 Sep 24;02(03):214-28. Available from: https://www.worldscientific.com/doi/abs/10.1142/ S2339547814500198

22. Menshawy A, Ismail A, Abdel-Maboud M, El-din AA, Elgebaly A, Gadelkarim M, et al. Effect of chlormadinone acetate versus drospirenonecontaining oral contraceptives on the endocrinal features of women with polycystic ovary syndrome: Systematic review and meta-analysis of randomized clinical trials. J Gynecol Obstet Hum Reprod [Internet]. 2019 Mar; Available from: https://linkinghub.elsevier.com/retrieve/pii/S24687 84718304732

23. Drake-Pérez M, Boto J, Fitsiori A, Lovblad K, Vargas MI. Clinical applications of diffusion weighted imaging in neuroradiology. Insights Imaging [Internet]. 2018 Aug 30;9(4):535-47. Available from: https://insightsimaging.springeropen.com/articles/ 10.1007/s13244-018-0624-3

24. Michielsen K, Vergote I, Op De Beeck K, Amant F, Leunen K, Moerman P, et al. Whole-body MRI with diffusion-weighted sequence for staging of patients with suspected ovarian cancer: A clinical feasibility study in comparison to CT and FDGPET/CT. Eur Radiol. 2014;24(4):889-901.

25. Zhuang Y, Wang T, Zhang G. Diffusion-weighted magnetic resonance imaging (DWI) parameters in benign and malignant ovarian tumors with solid and cystic components. J Coll Physicians Surg Pakistan. 2019;29(2):105-8 .

26. Sohaib SAA, Sahdev A, Trappen P Van, Jacobs IJ, Reznek RH. Characterization of Adnexal Mass Lesions on MR Imaging. Am J Roentgenol [Internet]. 2003 May;180(5):1297-304. Available from:

http://www.ajronline.org/doi/10.2214/ajr.180.5.18 01297

27. Bernardin L, Dilks P, Liyanage S, Miquel ME, Sahdev A, Rockall A. Effectiveness of semiquantitative multiphase dynamic contrastenhanced MRI as a predictor of malignancy in complex adnexal masses: radiological and pathological correlation. Eur Radiol [Internet]. 2012 Apr 18;22(4):880-90. Available from: http://link.springer.com/10.1007/s00330-0112331-z

28. Mohaghegh P, Rockall AG. Imaging Strategy for Early Ovarian Cancer: Characterization of Adnexal Masses with Conventional and Advanced Imaging Techniques. RadioGraphics [Internet]. 2012 Oct;32(6):1751-73. Available from: http://pubs.rsna.org/doi/10.1148/rg.326125520

29. Kurokawa, Ryo; Nakai, Yudai; Gonoi, Wataru; Mori, Harushi; Tsuruga, Tetsushi; Makise, Naohiro; Ushiku, Tetsuo; Abe, Osamu Differentiation between ovarian metastasis from colorectal carcinoma and primary ovarian carcinoma: Evaluation of tumour markers and "mille-feuille sign" on computed tomography/magnetic resonance imaging. European Journal of Radiology; 2020, 124(), 108823-. doi:10.1016/j.ejrad.2020.108823 